\title{
Genes associated with metabolic syndrome and hyperuricemia: An overview
}

\author{
Shabnam Pokharel ${ }^{1 *}$, Sanjeev Acharya ${ }^{2}$ and Abu Taiub Mohammed Mohiuddin Chowdhury ${ }^{3}$ \\ ${ }^{1}$ Department of Preventive Medicine, Jiamusi University, Heilongjiang Province, China \\ ${ }^{2}$ Department of Nephrology, $1^{\text {st }}$ Affiliated Hospital of Jiamusi University, Jiamusi city, Heilongiiang province, P. R China \\ ${ }^{3}$ Department of Digestive Disease, $1^{\text {st }}$ Affiliated Hospital of Jiamusi University, Jiamusi city, Heilongjiang Province, P.R China
}

\begin{abstract}
Purposes: Recently, different studies have found genetic basis for hyperuricemia, metabolic syndrome and different components of it. The purpose of our review is to overview the different genes that have been studied with regard to hyperuricemia, metabolic syndrome and its components.

Method: We made this review by systematically searching relevant literatures using multiple keywords and standardized terminology on PubMed, Nature.com, Hindawi.com, Plosone.com etc and other online resources related to the topic of our study.

Findings: Serum uric acid level is influenced by diet, cellular breakdown, renal elimination and correlates with metabolic syndrome, diabetes mellitus, blood pressure, gout, and cardiovascular disease. Metabolic syndrome has strong association with the development of type II diabetes and risk of cardiovascular morbidity and mortality.We found associations of different genes regarding hyperuricemia, metabolic syndrome and its components like diabetes mellitus, obesity, dyslipidemia, and hypertension.

Conclusions: This review provides evidence that different genes are responsible for the causation of Metabolic syndrome and its each component. Further genetic studies with different population groups and races in different parts of the world need to be carried out to find specific relation and effect of each gene in each specific component of our study.
\end{abstract}

\section{Introduction}

Metabolic syndrome (MetS) is a constellation of metabolic abnormalities, including abdominal obesity, hypertriglyceridemia, low high-density lipoprotein (HDL) concentrations, hypertension (HTN), and hyperglycemia [1], which has strong association with the development of type II diabetes and risk of cardiovascular morbidity and mortality [2,3]. Ford et al. reported that according to International Diabetes Federation (IDF) criteria the prevalence of MS is $23 \%$ in America, and $23.50 \%$ and $14.70 \%$ in urban and rural areas in China, respectively [4]. Prevalence and incidence of MetS has increased rapidly and become a major public health challenge worldwide [5]. The etiology of the MetS is complex, determined by the interplay of both genetic and environmental factors [6].

Accordingly, the prevalence of MetS is increasing in epidemic proportions in both developed countries and developing countries [7]. The worldwide prevalence of MetS in the adult population is estimated between 20\% and 25\% [8]. According to data from the National Health and Nutrition Examination Survey (NHANES) 2009-2010, about one-fifth of the adult population of the United States had high cardiometabolic risk, with the prevalence of MetS (adjusted for age) being estimated at $22.9 \%$ [9]. The prevalence of the MetS in the old aged population of China has reported to be $23 \%$ in men and $41 \%$ in women [10], about $21 \%$ in Chinese adults [11], 23.8\% in US Whites, $21.6 \%$ in African Americans, and $31.9 \%$ in Mexican Americans [12,13]. The increasing prevalence of MetS poses a serious public health problem worldwide. Genetic influences are thought to play a crucial role in MetS development, and as a result, genetic studies have become an active research area.

Uric acid (UA) is a metabolic product of purine. Serum uric acid level is influenced by diet, cellular breakdown, renal elimination and correlates with metabolic syndrome, diabetes, blood pressure, gout, and cardiovascular disease. Hyperuricemia has been associated with several metabolic and cardiovascular conditions, including diabetes and coronary artery disease [14]. Some large epidemiologic studies have shown that the prevalence of MetS was positively related to serum levels of UA (SUA) [15-17]. The association between uric acid and MetS is strong throughout human development. Epidemiological studies have demonstrated a close relationship between serum uric acid (SUA) levels and the presence of MetS (and several of its components) among children and adolescents as well as adults [18]. Some studies have even noted the strong association between SUA and carotid atherosclerosis among obese children $[18,19]$. One study analyzed the cross-sectional data of 1,370 US children and adolescents aged 12-17 years from the National Health and Nutrition Examination Survey (NHANES) 1999-2002 and found a graded positive association between SUA and the prevalence of MetS or its components, independent of classical

Correspondence to: Shabnam Pokharel, Department of Preventive Medicine, Jiamusi University, Heilongjiang Province, P.R China, E-mail: dramansanju@hotmail.com

Key words: genetics of metabolic syndrome, hyperuricemia, metabolic syndrome

Received: June 15, 2015; Accepted: July 21, 2015; Published: July 24, 2015 
risk factors. They found that of the five components of metabolic syndrome, SUA was significantly associated with abdominal obesity, hypertriglyceridemia, and hyperglycemia; there was only a borderline association observed between SUA and high blood pressure. Many data strongly suggest that uric acid may have a pathogenic role in the development of MetS and associated cardiovascular disease. Recent studies suggest that one of the mechanisms by which low birth weight increases the risk for hypertension and diabetes later in life is because low birth weight results in an elevation of uric acid that persists from birth throughout childhood.

The familial nature of MetS, the marked difference in the prevalence among various racial groups, and differences in concordance rates between monozygotic twins clearly suggested that MetS is under genetic control. Heritability estimates for MetS range from $10 \%$ to $42 \%$ [20]. For instance, the heritability of MetS was found to be $24 \%$ among 803 individuals from 89 Caribbean-Hispanic families in the Northern Manhattan Family Study [21], 42\% in 1,617 adult female twin pairs recruited from rural China with low MetS prevalence [22]. Genomewide association studies (GWAS) have led to a remarkable increase in replicable genetic association data for SUA and gout. Reduced renal excretion of urate is the major cause of hyperuricaemia and gout and most of the common genes discovered in GWAS are involved in the renal urate-transport system.

\section{Genetic risk factors for metabolic syndrome}

Genetic factors could influence the MetS itself or each individual component of it. A family history that includes obesity, Type 2 diabetes and/or insulin resistance greatly increases the chance that an individual will develop the MetS. However there are some genetic loci, which are in linkage disequilibrium with MetS.

\section{Genetics of metabolic syndrome}

Kissebah et al. performed a genomewide scan by use of a $10-\mathrm{cM}$ map in 2,209 individuals distributed over 507 nuclear Caucasian families and for the first identifying major genetic loci influencing the MetS phenotypes. They showed a quantitative trait locus (QTL) on chromosome 3q27 strongly linked to 6 traits: weight, waist circumference, leptin, insulin, insulin/glucose ratio, and hip circumference (lod scores ranging from 2.4 to 3.5). A second QTL was found on chromosome 17p12 and was strongly linked to plasma leptin levels $(\operatorname{lod}=5.0)[23]$.
McCarthy et al. studied 207 SNPs in 110 candidate genes among coronary artery disease patients, a population enriched for metabolic abnormalities. The number of abnormalities (0 to 5) was determined in 214 male and 91 female patients, and the association with each polymorphism was evaluated. Polymorphisms in 8 genes were associated with metabolic syndrome in the whole population (P values ranging from 0.047 to 0.008 ): LDLR, GBE1, IL1R1, TGFB1, IL6, COL5A2, SELE) and LIPC. Variants in 7 additional genes showed significant gene interaction by gender. Separate analyses in men and women revealed a strong association with a silent polymorphism in the gene encoding low density lipoprotein receptor-related proteinassociated protein-1 (LRPAP1) among females $(\mathrm{P}=0.0003)$, but not males $(\mathrm{P}=0.292)$ [24].

In a study of MetS of animal models Vartanian et al. found that Neill knockout mice were born at expected mendelian ratios and the phenotype of Neill -/- pups was normal through the first 4 to 6 months of life. At about 7 months, however, male Neill -/- mice developed severe obesity, and female Neill -/- mice were modestly overweight. Mutant mice also showed dyslipidemia, fatty liver disease, and a tendency to develop hyperinsulinemia, similar to metabolic syndrome in humans. Histologic studies showed significant kidney vacuolization, and mitochondrial DNA from Neill -/- mice showed increased levels of steady-state DNA damage and deletions, compared to wild type control [25]. Different genes for genetic association studies with metabolic syndrome are shown in Table 1 [26].

\section{Genetics of individual components of metabolic syndrome}

Genetic factors could influence each component of MetS individually. The genetic factors in obesity, uric acid/hyperuricemia, Hypertension, DM and dyslipidemia as the main causes of MetS are relieved in short here.

\section{Genetic predisposition to obesity}

The high incidence of obesity could be explained by a [thrifty genotype] hypothesis: over periods of time the alleles were selected which favored weight gain and fat storage in order to provide enough nutrients for times of food deprivation. In today's times of food availability and decreased physical activity such genotypes cause obesity. Besides monogenic forms of obesity, there are at least 20 rare syndromes with obvious genetic basis, which appears to be more complex as it predisposes more dysfunctions (mental retardation, multiple signs of hypothalamic disorder).

Table 1. Different genes for genetic association studies with metabolic syndrome.

LOW DENSITY LIPOPROTEIN RECEPTOR (LDLR) gene. The low density lipoprotein receptor is a cell surface receptor that plays an important role in cholesterol homeostasis. Mutations in this gene are associated with familiarly hypercholesterolemia.

GLYCOGEN BRANCHING ENZYME (GBE1) gene. The GBE1 gene encodes the glycogen branching enzyme (EC 2.4.1.18), which is involved in glycogen synthesis. Branching of the glycogen chains is essential to pack a very large number of glycosyl units into a relatively soluble spherical molecule of glycogen.

INTERLEUKIN 1 RECEPTOR, TYPE I (IL1R1) gene. Interleukin-1 consists of 2 separate but related proteins, IL1-alpha and IL1-beta. Both contain a single membrane-spanning segment, a large cytoplasmic region, and an extracellular domain. IL 1 is one of mediators in inflammation.

TRANSFORMING GROWTH FACTOR, BETA-1 (TGFB) gene. This gene encodes the multifunctional peptide that controls proliferation, differentiation, and other functions in many cell types. TGFB acts synergistically with TGFA in inducing transformation. It also acts as a negative autocrine growth factor. Dysregulation of TGFB activation and signaling may result in apoptosis.

INTERLEUKIN 6 (IL6) gene. IL6 is an immunoregulatory cytokine that activates a cell-surface signaling assembly composed of IL6, IL6RA, and the shared signaling receptor gp130. The aberrant production of IL6 by neoplastic cells has been implicated as a strong contributory factor to the growth of multiple myeloma and other B-cell dyscrasias, T-cell lymphoma, renal and ovarian cell carcinomas, and Kaposi sarcoma demonstrated repression of the IL6 gene promoter by p53. IL6 gene is one of the candidate genes for linkage studies of osteopenia and osteoporosis because the gene product stimulates osteoclasts through binding to its cell surface receptor (IL6R).

COLLAGEN, TYPE V, ALPHA-2 (COL5A2) gene. SELECTIN E (SELE) gene. Endothelial leukocyte adhesion molecule-1 is expressed by cytokine-stimulated endothelial cells. It is thought to be responsible for the accumulation of blood leukocytes at sites of inflammation by mediating the adhesion of cells to the vascular lining.

HEPATIC LIPOPROTEIN LIPASE (LIPC) gene. Hepatic lipase, like lipoprotein lipase and lecithin:cholesterolacyltransferase, plays a major role in the regulation of plasma lipids. Rare deficiencies of all of these enzymes have been identified in man, and all are associated with pathologic levels of circulating lipoprotein particles. 
The common human obesity is thought to be oligogenic state and its expression is modulated by multiple modifier genes and by environmental factors: food intake, physical activity, and smoking. Genetic basis in the pathophysiology of obesity is estimated to be 40$80 \%$. At least 204 putative gene loci associated with obesity have been identified, and those, which have been confirmed by multiple studies, are presented in Table 2 [26].

\section{Genetic predisposition to hyperuricemia}

Elevated serum uric acid is a risk factor for gout and is independently associated with cardiovascular disease in the general population and is also linked to insulin resistance, type 2 diabetes, MetS and obesity. Although conventional factors, including age, body mass index (BMI), alcohol consumption and cigarette smoking, contribute greatly to variations in SUA concentrations [27], genetic determinants also play roles, and heritability as high as $42 \%$ have been reported [28]. Moreover, genetic studies facilitate the development of effective treatments for associated diseases. Recently, advances have been made in identifying genes regulating SUA through GWAS. The first wave of discovery of uric acid genes was conducted with European populations, identifying the associations of SLC2A9, ABCG2, and SLC17A3 with SUA concentrations [29-31]. In addition, many GWAS focusing on SUA concentrations in individuals of European decent have identified several novel associated loci mapped in or near SLC17A1, SLC22A11, SLC22A12, SLC16A9, LRRC16A, GCKR, R3HDM2- INHBC, and RREB1 [32-34].

In a study done at Shanghai, China which aimed to evaluate the associations between these loci and serum uric acid concentrations, fourteen single nucleotide polymorphisms (SNPs) mapped in or near 11 loci (PDZK1, GCKR, LRP2, SLC2A9, ABCG2, LRRC16A, SLC17A1, SLC17A3, SLC22A11, SLC22A12 and SF1) were genotyped in 2329 Chinese subjects. Serum biochemical parameters including uric acid concentrations were determined. All the variants were analyzed for gender differences since uric acid metabolism differed between genders. The meta-analysis for combined data from both males and females revealed that rs3775948 and rs606458 were associated with the uric acid concentrations $\mathrm{P}=0.036$ and 0.043 , respectively. Study concluded that the SLC2A9 rs11722228, SF1 rs606458 and GCKR rs780094 variants modulate uric acid concentrations in Chinese males,

Table 2. Genetic predisposition to obesity.

\begin{tabular}{|l|c|}
\hline $\begin{array}{l}\text { Gene name (accord. to HUGO } \\
\text { nomenclature committee) }\end{array}$ & Protein name \\
\hline ADIPOQ & Adiponectin \\
\hline ADRA2A & Adrenergic receptor $\alpha$-2A \\
\hline ADRA2B & Adrenergic receptor $\alpha$-2B \\
\hline ADRB1 & Adrenergic receptor $\beta-1$ \\
\hline ADRB2 & Adrenergic receptor $\beta-2$ \\
\hline ADRB3 & Adrenergic receptor $\beta-3$ \\
\hline DRD2 & Dopamine receptor D2 \\
\hline LEP & Leptin \\
\hline LEPR & Leptin receptor \\
\hline NR3C1 & member 1 \\
\hline PPARG & PPAR- $\gamma$ \\
\hline UCP1 & Uncoupling protein 1 \\
\hline UCP2 & Uncoupling protein 2 \\
\hline UCP3 & Uncoupling protein 3 \\
\hline TNF & TNF- $\alpha$ \\
\hline LIPE & Hormone sensitive lipase \\
\hline
\end{tabular}

while SF1 rs606458 and SLC2A9 rs3775948 are associated with the uric acid concentrations in both Chinese males and females [35].

The genes for the urate transporters, GLUT-9 and ABCG2, which are important modulators of uric acid levels, consistently associate with serum uric acid levels and gout. Although the GWAS association data for SLC22A12 (which encodes URAT1) have been less impressive, many layers of evidence indicate that URAT1 is an essential component of renal urate handing. Loss-of-function mutations in the absorptive transporter genes SLC22A12 or SLC2A9 lead to a dominance of urate secretion and hypouricaemia, whereas loss-in-function or reductionin-function mutations in the secretory urate transporter genes, ABCG2, SLC17A1 or SLC17A3, cause hyperuricaemia. These findings indicate that serum uric acid levels are largely determined by the relative balance between urate absorption and secretion across the proximal tubule [36].

\section{Genetics of hypertension}

Genetics of hypertension is complex with no known single gene playing a major role, but rather many genes each with mild effects reacting to different environmental stimuli contribute to blood pressure. The heritable component of blood pressure has been documented in familial and twin studies suggesting that $30 \%-50 \%$ of the variance of blood pressure readings is attributable to genetic heritability and about $50 \%$ to environmental factors. Early studies in hypertension identified specific enzymes, channels and receptors implicating sodium handling in the regulation of blood pressure. It included genes involved with the renin-angiotensin-aldosterone system controlling blood pressure and salt-water homeostasis, proteins in hormonal regulation of blood pressure and proteins coded by genes involved in the structure and/ or regulation of vascular tone (endothelins and their receptors). The field of molecular genetics has revolutionized the study of hypertension by identifying single gene syndromes or Mendelian forms and several candidate genes for blood pressure variance. Genes have been localized to at least 20 chromosome regions. For example, recent GWAS of common genetic variants found 13 single nucleotide polymorphisms (SNPs) or variants in systolic and 20 for diastolic blood pressure readings representing different genes and genetic heterogeneity.

The CYP17A1 gene: It is located on chromosome 10q24.3, consisting of eight exons and seven introns, and is primarily expressed in the adrenal glands and gonads. The CYP17A1 gene produces the $\mathrm{P} 450 \mathrm{c} 17$ protein, which is a key enzyme in the steroid-genic pathway that produces sex hormones. Some evidence has indicated that the levels of sex hormones could affect the development of cardiovascular and cerebrovascular diseases [37]. This gene was shown to be consistently and significantly associated with SBP and DBP in the two large GWA meta-analyses, the Cohorts for Heart and Aging Research in Genome Epidemiology (CHARGE) Consortium and the Global Blood Pressure Genetics (Global BPgen) Consortium, and subsequently crossvalidated in Korean and Japanese populations [38,39].

ATP2B1 gene: GWAS studies showed that the rs2681472 polymorphism near the ATP2B1 gene was associated with hypertension susceptibility in Europeans. The meta-analysis confirmed that there is a significant association of the ATP2B1 gene polymorphism with hypertension susceptibility in East Asians [40].

The STK39 gene: It encodes the Ste20-related prolinealaninerich kinase (SPAK) protein, which may regulate BP by increasing its expression and altering renal sodium excretion through its interaction with WNK kinase and cation-chloride cotransporters. A meta-analysis 
shows the significant association of STK39 polymorphism with susceptibility to hypertension in Europeans and East Asians [41].

WNK4 gene: It is mapped to chromosome 17 with 19 exons and spanning $16 \mathrm{~kb}$ of genomic DNA12. It is suggested that WNK4 is expressed almost exclusively in the kidney, and specifically localizes to the distal convoluted tubule (DCT) and the cortical collecting duct (CCD), the segment of the distal nephron involved in regulating the ion homestasis. Loss-of-function mutations of WNK4 may cause increased $\mathrm{Na}-\mathrm{Cl}$ co-transporter (NCC) expression in the DCT and increase paracellular $\mathrm{Cl}-$ permeability in the distal tubule and reduce the surface expression of ROMK channels [42]. The over activity of NCC resulted of $\mathrm{Na}+$ retention in the DCT contributing to development of hypertension.

\section{Genetic predisposition to diabetes mellitus}

Type 1 diabetes is an autoimmune disease characterized by antibody-mediated and cell-mediated destruction of pancreatic islets. Type 1 diabetes may occur at any age but is common in childhood, usually presenting before age 30 years. Type 2 diabetes is characterized by a combination of insulin resistance and insulin deficiency. The metabolic syndrome (insulin resistance, visceral obesity, hypertension, hyperuricemia, and dyslipidemia with high triglyceride levels and low amounts of high-density lipoprotein) is often followed by type 2 diabetes. For a long period, insulin resistance is compensated by increased insulin secretion, but a gradual decline in pancreatic $\beta$-cell function finally culminates in hyperglycemia, and type 2 diabetic patients require treatment with insulin. Type 2 diabetes was typically a disease of mostly elderly adults, but recently it is increasingly seen in adolescents and even in children. In addition, other types of DM include maturity-onset diabetes of the young, gestational diabetes, and diabetes secondary to various metabolic disorders or the result of corticosteroid treatment. Now, there has been found a lot of genetic basis for the causation of different types of DM.

Affected genes in monogenic forms of diabetes, insulin resistance and lipodystrophy represent an excellent base for the search of susceptibility genes for polygenic multifactorial Type $2 \mathrm{DM}$, although the latter can be distinguished from monogenic Mendelian diseases. Namely, on certain genetic backgrounds, with particular gene interaction - epistasis and with certain environment influence the same genes could contribute to Type 2 DM.

Maturity-onset diabetes of the young (MODY) is a monogenic from of diabetes and exists in 6 forms due to 6 affected MODY genes. From them, HNF4A, TCF1 (or HNF1A) and GCK genes which encode for two transcriptional factors and glucokinase in the $\beta$-cells, respectively were reliably proved to be involved in DM2.

PPAR $\gamma$ (peroxisome proliferator-activated receptor- $\gamma$ ). This gene has been widely studied because it is important in adipocyte and lipid metabolism. One form of the PPAR $\gamma$ gene (Pro) decreases insulin sensitivity and increases Type 2DM risk by several fold. Perhaps more importantly is that this variant is very common in most populations. Approximately $98 \%$ of Europeans carry at least one copy of the Pro allele. Thus, it likely contributes to a considerable proportion ( 25\%) of Type 2DM that occurs, particularly among Caucasians.

ABCC8 (ATP binding cassette, subfamily C, member 8). This gene encodes the high-affinity sulfonylurea receptor (SUR1) subunit that is coupled to the Kir6.2 subunit (encoded by KCNJ11, also known as the potassium channel, inwardly rectifying subfamily J, member 11). Both genes are part of the ATP-sensitive potassium channel, which plays a key role in regulating the release of hormones, such as insulin and glucagon, in the beta cell. Mutations in either gene can affect the potassium channel's activity and insulin secretion, ultimately leading to the development of Type 2DM.

CAPN10 (calpain 10). CAPN10 encodes an intracellular calciumdependent cysteine protease that is ubiquitously expressed [43]. A haplotype that was initially linked to Type 2DM included an intronic A to $\mathrm{G}$ mutation at position 43 , which appears to be involved in CAPN10 transcription. Physiological studies suggest that variations in calpain 10 activity effects insulin secretion, and therefore, susceptibility to Type 2DM.

\section{Genetic predisposition to dyslipidemia}

Lipid metabolism is regulated by several factors, such as apolipoproteins, lipoprotein receptors, enzymes, and transfer proteins. Many genetic investigations have been performed in large-scale studies, which revealed the close associations between genetic abnormalities of the above-mentioned factors and a variety of dyslipidemic disorders. In recent years, novel genes which regulate cholesterol metabolism were being reported like proprotein convertase subtilisin/kexin type 9 (PCSK9) and autosomal recessive hypercholesterolemia (ARH), found as causal genes in patients whose phenotypes are similar to familial hypercholesterolemia. Niemann-Pick C1-Like 1 (NPC1L1), ATP-binding cassette (ABC) A1 (ABCA1), and G5/G8 (ABCG5/G8) were also identified as cholesterol transporters in intestinal epithelial cells and hepatocytes. NPC1L1 is recognized as a target of ezetimibe, a cholesterol absorption inhibitor classified into a new class of lipidlowering agents [44].

A study was done in Japan to identify genetic variants that confer susceptibility to dyslipidemia. The genotypes for 100 polymorphisms of 65 candidate genes were determined. The chi(2) test and multivariable logistic regression analysis revealed that seven polymorphisms of APOA5, APOC3, APOA1, ACAT2, and LPL were significantly associated with hypertriglyceridemia, six polymorphisms of APOA5, LIPC, and CYP3A4 with low HDL-cholesterol, and three polymorphisms of APOE and CCR2 with high LDL-cholesterol in subject panel A. For validation of these associations, the same polymorphisms were examined in subject panel B. These results indicate that polymorphisms of APOA5, APOC3, APOA1, and LPL are determinants of hypertriglyceridemia and that those of APOA5 and APOE are determinants of low HDL-cholesterol and high LDLcholesterol, respectively, in Japanese individuals [45].

Anti-hypertensive treatment with beta adrenergic receptor (AR) blockers has been associated with a higher incidence of diabetes, hypercholesterolemia and hypertriglyceridemia. The Beta 2 AR gene displays high genetic variability and common polymorphisms at codons such as Arg16Gly or Glu27Gln and Thr164Ile which could result in altered receptor function. A study done by Laccarino et al. demonstrate that hypertensive patients bearing the Glu27variant of b2AR gene and treated with b-blockers show a higher incidence of dyslipidemia. This result allows the identification of patients at high risk to develop metabolic complications to chronic b-blockade treatment[46].

\section{Conclusion}

This review provides evidence that different genes are responsible for the causation of MetS and different components of it. When studying the importance of particular susceptibility genes one must bear in mind that their effect is modest and different factors may affect 
it. Further genetic studies with different population groups and races in different parts of the world are neededto be carried out to find specific relation of each gene regarding each specific component of our study. The listed susceptibility genes does contribute to the basis for future diagnosis, prognosis and therapy for hyperuricemia and MetS, but the mutual influences of various gene loci and interactions of genes with dietary, environmental and other lifestyle factors remain to be exactly determined and quantitated.

\section{References}

1. Chen CC, Lin WY, Li CI, Liu CS, Li TC, et al. (2012) The association of alcohol consumption with metabolic syndrome and its individual components: the Taichung community health study. Nutr Res 32: 24-29. [Crossref]

2. Hanson RL, Imperatore G, Bennett PH, Knowler WC (2002) Components of the "metabolic syndrome" and incidence of type 2 diabetes. Diabetes 51: 3120-3127. [Crossref]

3. Gami AS, Witt BJ, Howard DE, Erwin PJ, Gami LA, et al. (2007) Metabolic syndrome and risk of incident cardiovascular events and death: a systematic review and metaanalysis of longitudinal studies. J Am Coll Cardiol 49: 403-414. [Crossref]

4. Ford ES, Giles WH, Dietz WH (2002) Prevalence of the metabolic syndrome among US adults: findings from the third National Health and Nutrition Examination Survey. JAMA 287: 356-359. [Crossref]

5. Alberti KG, Zimmet P, Shaw J (2006) Metabolic syndrome--a new world-wide definition. A Consensus Statement from the International Diabetes Federation. Diabet Med 23: 469-480. [Crossref]

6. Liese AD, Mayer-Davis EJ, Haffner SM (1998) Development of the multiple metabolic syndrome: an epidemiologic perspective. Epidemiol Rev 20: 157-172. [Crossref]

7. Cornier MA, Dabelea D, Hernandez TL, Lindstrom RC, Steig AJ, et al. (2008) The metabolic syndrome. Endocr Rev 29: 777-822. [Crossref]

8. International Diabetes Federation (2006) The IDF consensus worldwide definition of the metabolic syndrome.

9. Beltrán-Sánchez H, Harhay MO, Harhay MM, McElligott S (2013) Prevalence and trends of metabolic syndrome in the adult U.S. population, 1999-2010. J Am Coll Cardiol 62: 697-703. [Crossref]

10. Zhuo Q, Wang ZQ, Fu P, Piao JH, Tian Y, et al. (2010) Association between adiponectin and metabolic syndrome in older adults from major cities of China. Biomed Environ Sci 23: 53-61. [Crossref]

11. Xu WH, Ruan XN, Fu XJ, Zhu QL, Zhang H, et al. (2010) Prevalence of the metabolic syndrome in Pudong New Area of Shanghai using three proposed definitions among Chinese adults. BMC Public Health 10: 246. [Crossref]

12. Ford ES, Giles WH, Dietz WH (2002) Prevalence of the metabolic syndrome among US adults: findings from the third National Health and Nutrition Examination Survey. JAMA 287: 356-359. [Crossref]

13. Lorenzo C, Williams K, Hunt KJ, Haffner SM (2007) The national cholesterol dducation program - adult treatment panel III, international diabetes federation, and world health organization definitions of the metabolic syndrome as predictors of incident cardiovascular disease and diabetes. Diabetes Care 30: 8-13. [Crossref]

14. Choi HK, Ford ES (2007) Prevalence of the metabolic syndrome in individuals with hyperuricemia. Am J Med 120: 442-447. [Crossref]

15. Yoo TW, Sung KC, Shin HS, Kim BJ, Kim BS, et al. (2005) Relationship between serum uric acid concentration and insulin resistance and metabolic syndrome. Circ $J$ 69: 928-933. [Crossref]

16. Ishizaka N, Ishizaka Y, Toda E, Nagai R, Yamakado M (2005) Association between serum uric acid, metabolic syndrome, and carotid atherosclerosis in Japanese individuals. Arterioscler Thromb Vasc Biol 25: 1038-1044. [Crossref]

17. Boyko EJ, de Courten M, Zimmet PZ, Chitson P, Tuomilehto J, et al. (2000) Features of the metabolic syndrome predict higher risk of diabetes and impaired glucose tolerance: a prospective study in Mauritius. Diabetes Care 23: 1242-1248. [Crossref]

18. Ford ES, Li C, Cook S, Choi HK (2007) Serum concentrations of uric acid and the metabolic syndrome among US children and adolescents. Circulation 115: 2526-2532. [Crossref]

19. Pacifico L, Cantisani V, Anania C, Bonaiuto E, Martino F, et al. (2009) Serum uric acid and its association withmetabolic syndrome and carotid atherosclerosis in obese children. Eur J Endocrinol 160: 45-52. [Crossref]

20. Bosy-Westphal A, Onur S, Geisler C, Wolf A, Korth O, et al. (2007) Common familial influences on clustering of metabolic syndrome traits with central obesity and insulin resistance: the Kiel obesity prevention study. Int J Obes (Lond) 31: 784-790. [Crossref]

21. Lin HF, Boden-Albala B, Juo SH, Park N, Rundek T, et al. (2005) Heritabilities of the metabolic syndrome and its components in the Northern Manhattan Family Study. Diabetologia 48: 2006-2012. [Crossref]

22. Zhang S, Liu X, Yu Y, Hong X, Christoffel KK, et al. (2009) Genetic and environmental contributions to phenotypic components of metabolic syndrome: a population-based twin study. Obesity (Silver Spring) 17: 1581-1587. [Crossref]

23. Kissebah AH, Sonnenberg GE, Myklebust J, Goldstein M, Broman K, et al. (2000) Quantitative trait loci on chromosomes 3 and 17 influence phenotypes of the metabolic syndrome. Proc Natl Acad Sci U S A 97: 14478-14483. [Crossref]

24. McCarthy J, Meyer J, Moliterno DJ, Newby LK, Rogers WJ,et al. (2003) Evidence for substantial effect modification by gender in a large-scale genetic association study of the metabolic syndrome among coronary heart disease patients. Hum Genet 114: 87-98. [Crossref]

25. Vartanian V, Lowell B, Minko IG, Wood TG, Ceci JD, et al. (2006) The metabolic syndrome resulting from a knockout of the NEIL1 DNA glycosylase. Proc Natl Acad Sci U S A103: 1864-1869. [Crossref]

26. Genetic susceptibility to metabolic syndrome. Janja Marc, University of Ljubljana, Faculty of pharmacy, Ljubljiana, Slovenia.

27. Haj Mouhamed D, Ezzaher A, Neffati F, Douki W, Gaha L, et al. (2011) Effect of cigarette smoking on plasma uric acid concentrations. Environ Health Prev Med 16: 307-312. [Crossref]

28. Nath SD, Voruganti VS, Arar NH, Thameem F, Lopez-Alvarenga JC, et al. (2007) Genome scan for determinants of serum uric acid variability. J Am Soc Nephrol 18: 3156-3163. [Crossref]

29. Döring A, Gieger C, Mehta D, Gohlke H, Prokisch H, et al. (2008) SLC2A9 influences uric acid concentrations with pronounced sex-specific effects. Nat Genet 40: 430-436. [Crossref]

30. VitartV, Rudan I, Hayward C, Gray NK, Floyd J, et al. (2008) SLC2A9 is a newly identified urate transporter influencing serum urate concentration, urate excretion and gout. Nat Genet 40: 437-442. [Crossref]

31. Dehghan A, Köttgen A, Yang Q, Hwang SJ, Kao WL, et al. (2008) Association of three genetic loci with uric acid concentration and risk of gout: a genome-wide association study. Lancet 372: 1953-1961. [Crossref]

32. Kolz M, Johnson T, Sanna S, Teumer A, Vitart V, et al. (2009) Meta-analysis of 28,141 individuals identifies common variants within five new loci that influence uric acid concentrations. PLoS Genet 5: e1000504. [Crossref]

33. Yang Q, Köttgen A, Dehghan A, Smith AV, Glazer NL, et al. (2010) Multiple genetic loci influence serum urate levels and their relationship with gout and cardiovascular disease risk factors. Circ Cardiovasc Genet 3: 523-530. [Crossref]

34. Karns R, Zhang G, Sun G, Rao Indugula S, Cheng H, et al. (2012) Genome-wide association of serum uric acid concentration: replication of sequence variants in an island population of the Adriatic coast of Croatia. Ann Hum Genet 76: 121-127. [Crossref]

35. Sun X, Jiang F, Zhang R, Tang SS, Chen M, et al. (2014) Serum uric acid levels are associated with polymorphisms in the SLC2A9, SF1, and GCKR genes in a Chinese population. Acta Pharmacol Sin 35: 1421-1427. [Crossref]

36. Reginato AM, Mount DB, Yang I, Choi HK (2012) The genetics of hyperuricaemia and gout. Nat Rev Rheumatol 8: 610-621. [Crossref]

37. Fan Y, Laaksonen R, Janatuinen T, Vesalainen R, Nuutila P, et al. (2001) Hepatic lipase gene variation is related to coronary reactivity in healthy young men. Eur J Clin Invest 31: 574-580. [Crossref]

38. Hong KW, Jin HS, Lim JE, Kim S, Go MJ, et al. (2010) Recapitulation of two genomewide association studies on blood pressure and essential hypertension in the Korean population. J Hum Genet 55: 336-341. [Crossref]

39. Takeuchi F, Isono M, Katsuya T, Yamamoto K, Yokota M, et al. (2010) Blood pressure and hypertension are associated with 7 loci in the Japanese population. Circulation 121: 2302-2309. [Crossref] 
40. Xi B, Tang W, Wang Q (2012) Polymorphism near the ATP2B1 gene is associated with hypertension risk in East Asians: a meta-analysis involving 15909 cases and 18529 controls. Blood Press 21: 134-138. [Crossref]

41. Xi B, Chen M, Chandak GR, Shen Y, Yan L, et al. (2013) STK39 polymorphism is associated with essential hypertension: a systematic review and meta-analysis. PLoS One 8: e59584. [Crossref]

42. Flatman PW (2008) Cotransporters, WNKs and hypertension: an update. Curr Opin Nephrol Hypertens 17: 186-192. [Crossref]
43. Cox NJ, Hayes MG, Roe CA, Tsuchiya T, Bell GI (2004) Linkage of calpain 10 to type 2 diabetes: the biological rationale. Diabetes 53: S19-25. [Crossref]

44. Hirayama S, Miida T (2013) [Genetic predisposition to dyslipidemia]. Rinsho Byori 61: 159-166. [Crossref]

45. Yamada Y, Matsuo H, Warita S, Watanabe S, Kato K, et al. (2007) Prediction of genetic risk for dyslipidemia. Genomics 90: 551-558. [Crossref]

46. Iaccarino G, Trimarco V, Lanni F, Cipolletta E, Izzo R, et al. (2005) beta-Blockade and increased dyslipidemia in patients bearing Glu27 variant of beta2 adrenergic receptor gene. Pharmacogenomics J 5: 292-297. [Crossref]

Copyright: $(2015$ Pokharel S. This is an open-access article distributed under the terms of the Creative Commons Attribution License, which permits unrestricted use, distribution, and reproduction in any medium, provided the original author and source are credited. 